\title{
The Importance Of COVID-19 Testing to Assess Socioeconomic Fatality Drivers and True Case Fatality Rate: Facing the Pandemic or Walking in the Dark?
}

\author{
Cristina Isabel Ibarra-Armenta \\ Universidad Autonoma de Sinaloa \\ Moises Alejandro Alarcon-Osuna \\ Universidad De Guadalajara
}

\begin{abstract}
Europe and other developed countries have become the center of the pandemic while other developing and less developed regions have a low spread of COVID-19. The case fatality rate (CFR) differs among countries; genetics, health systems, population characteristics, public health, and social measures are believed to be the determinants of such diversity. Through an ordinal probit, cross-section, and panel data models for 71 countries, it is shown that countries with more tests per million inhabitants are also those reporting more cases and deaths, and greater testing helped reduce CFR. However, health infrastructure and population health indicators are not confirmed drives for CFR. Our main finding is that the pandemic concentration in developed nations is highly related to their ability and resources for tracking the pandemic. In conclusion, the true CFR drivers at national levels cannot be estimated without increasing the number of tests per million inhabitants. Also, countries with more testings are identifying the reality of the pandemic while others with fewer testings are still walking in the dark. Lastly, lockdown measures are effective at reducing the mortality rate.
\end{abstract}

Keywords: COVID-19 testing, case fatality rate, health infrastructure, OECD, stringency index

\section{BACKGROUND}

The COVID-19 outbreak has disrupted economic and social life all over the world, and while its scope is not yet certain, it is definitively deep and lasting. Governments, policymakers, politicians, physicians, medical employees, scientists and international organisations have gathered together into a virtual space to collaborate and find answers to all the raised questions. Apart from defeating the virus by developing a vaccine and/or finding a drug largely effective for patients with COVID-19, among the most important of governments' concerns in the short- term is the impact of COVID-19 on the health system, namely, the availability of health infrastructure, as well as finding the best strategy for reducing as much as possible the effects of the pandemic in economic and social aspects. The World Health Organization (WHO) has recommended social distancing measures to slow the spread of the virus and thereby prevent the collapse of medical services. However, in the long-term, the WHO 
expects that the virus will remain present with periods of low-level infections, perhaps with seasonal increments (WHO, 2020). Therefore, governmental strategies should aim to ensure that health services are available to attend COVID-19 patients without compromising all the other health services in the medium- and long-term. In a document published on 15th April by the WHO (2020), a set of recommended actions for public policies are outlined in which the continuous tracking of the virus is recommended to be able take regional public health and social measures, so-called lockdowns, only at high-risk regions, or places where contagions return high. At the centre of the recommendations is the importance of testing (Sanchez, 2020) and the use of serological tests in line with scientific recommendations (CDC, 2020). Likewise, the Organisation for Economic Cooperation and Development (OECD) (2020) highlights the importance of testing by presenting an analysis of a better performance observed in countries with a high number of tests per million inhabitants. It is also pointed out that the increase in tests will help gather essential information to study the virus, especially to determine whether the population is developing antibodies, whether the virus can mutate and how to deal with COVID-19 in the following months. In addition, it is particularly important to find the asymptomatic proportion in the population, first to assess the probability of contagion from such individuals to others and, second, to estimate the true CFR.

There is great diversity in the public health and social measures taken by each country against the pandemic, which can be grouped into three lines of action: ensure a good supply of medical equipment and vacate the hospitals as much as possible; social distancing measures, from banning international travel, suspending schools, encouraging teleworking, etc.; and economic measures taken to guarantee the wellbeing of the population, with special support for firms and families. Naturally, not all countries have followed the same set of actions. In fact, there are wide differences in the economic and social distance measures. Some countries implemented severe restrictions once the domestic contagions increased considerably, such as Italy, France, and the United Kingdom, whereas Peru and the United States (US) closed international airports shortly after the first COVID-19 case was confirmed; however. this measure was not that effective, especially for the latter. Others implemented massive testing preventing the cases from exponential increase, such as Iceland, Singapore and Korea (OECD, 2020). Additionally, among the countries with a larger number of applied tests is Luxemburg, which has recently been published to test all its population ${ }^{1}$.

In addition, law enforcement capacity and political organisation might have also played a significant role in this regard. For instance, in Mexico and the US, sub-national governments could regulate regional social distance measures. Meanwhile, the economic organisation, informality and the limited or null presence of the welfare state hinder the social and economic lockdown (Loayza, 2020), namely, entrepreneurs and employees in the informal economy might not access economic aid ${ }^{2}$. According to the International Labour Organization (ILO), more than $60 \%$ of employment in the world is informal; this cohort, by region, includes Africa (85.8\% of employment is informal), Asia and the Pacific (68.2\%), Arab States (68.6\%), the Americas (40.0\%) and 25.1\% in Europe and Central Asia ${ }^{3}$. In addition, according to Loayza (2020), in developing countries, lockdown measures are less effective for several reasons, namely, people will continue to work if their income is compromised, confinement in overcrowded dwellings with poor sanity access might increase the risk of contagion and displacement of people from urban to rural areas would move the contagions spreads to rural areas, which frequently have less access to medical services and sanity.

It is important to note that there are 70 countries in the sample, and they concentrate $96 \%$ of confirmed cases worldwide. The distribution is shown in Figure 1. It is clear that the majority of cases are concentrated in developed countries while developing economies only account for approximately $20 \%$ of the cases. Africa registered only $1 \%$ of worldwide cases. 
FIGURE 1

PROPORTION OF CASES BY COUNTRY AS OF 7TH MAY 2020

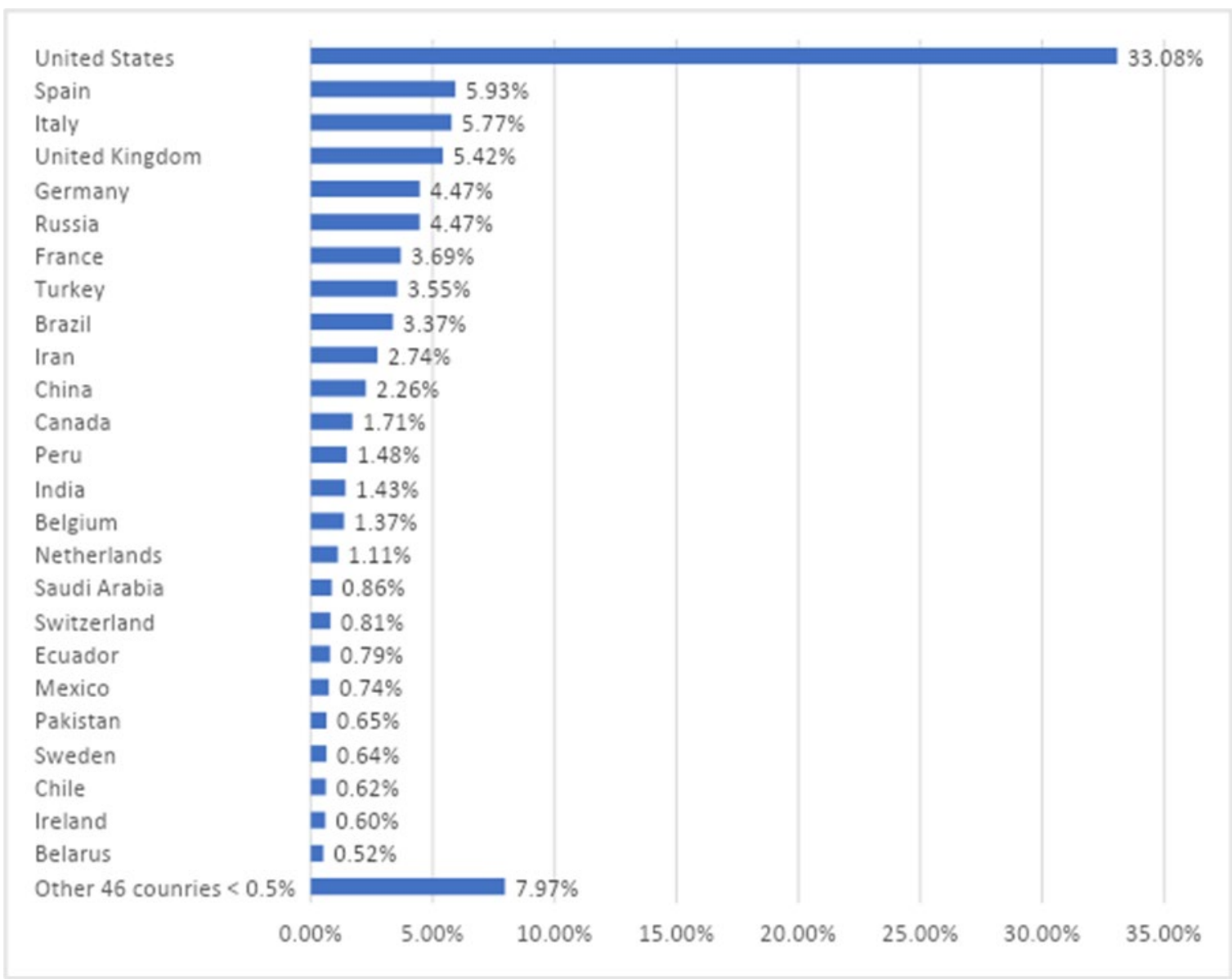

Source: own elaboration with data from Ourworldindata.org

From the initial analysis presented with the Chinese experience, it has been stated that the health of individuals as well as their age are important drivers for virus fatalities (The Novel, 2020). However, there is still little evidence about the correlation between the aggregated indicators of population health and health infrastructure and fatalities.

Resuming, the effectiveness of lockdown measures has been questioned, given that it is likely that the virus will continue to spread in the long-term, bringing huge economic losses. The likely under identification of cases in developing nations would prevent further control of the virus in the long-term. Additionally, public responses might be more effective, as better knowledge of driving socioeconomic determinants is found, for which further data need to be generated. Consequently, this paper attempts to fill a gap in the literature by assessing whether COVID -19 testing, lockdown measures and socioeconomic country characteristics are strong drivers of CFR, cases and deaths worldwide.

The paper is organised as follows: in the second section, the materials and methods are explained, the third section presents the results, the fourth section presents a discussion and the fifth section summarises the conclusions and policy implications. 


\section{METHODS}

\section{Data}

The analysed data were retrieved from different sources. For COVID-19 cases and testing, the data came from ourwoldindata.org in combination with $\mathrm{GitHub}^{4}$ the last date included is 7 th May 2020. For health indicators, the $\mathrm{OECD}^{5}$ and $\mathrm{WHO}^{6}$ databases were consulted. The data collected correspond to the most recent data available.

For the cross-section models, the countries included are those that reported a 3-day average of three new deaths in at least one day. This criterion has been made to take out of the sample those countries in which COVID-19 has not been widely spread until now. Upon this criterion, a sample of 71 countries was obtained; the full list is available as Additional file 4. A subsample for the OECD was also built. Not all OECD members were included due to lack of information or because they $\mathrm{did}$ not meet the abovementioned criterion for COVID-19 deaths. For the panel data analysis, all available information was used, yet given that many countries do not report daily ciphers or they do not change over time, the sample is smaller (reduced to 66). A full list of the countries used per model is presented as Additional file 4.

\section{Ordinal Probit Model Specification}

An ordinal probit model allows the use of an ordinal list as a dependent variable, which can be numeric or categorical. The model was estimated with Stata. The dependent variable for this model is the CFR, which takes values from 1 to $N$, where 1 is assigned to the countries with the lowest CFR.

The estimation of CFR is difficult for several reasons, the first being the universe of confirmed cases. Due to the very different criteria for test applications, in most countries, tests are administered only to those presenting symptoms, at least fever, or those requiring hospitalisation. Therefore, the universe of cases is well underestimated. Nonetheless, there is still no agreement over the likely size of this underestimation; depending on the study, the asymptomatic cases are estimated to be between $5 \%$ and $80 \%$ (Heneghan, Brassey and Jefferson, 2020). For instance, Iceland is the country with more tests applied per million inhabitants due to a massive testing strategy. In this case, they identified $50 \%$ of the positive cases as asymptomatic (Heneghan, Brassey and Jefferson, 2020). In the case of the Diamond Princess cruise ship, the proportion of asymptomatic to total infected was estimated to be $17.9 \%$ (Mizumoto, Kagaya, Zarebski a n d Chowel, 2020). The second difficulty comes with differences in death registers ${ }^{7}$. Some countries recognise COVID-19 death as suspicious if the deceased lived with a COVID-19 patient or was closely related; meanwhile, other countries only account for the confirmed cases. Third, the timing matters. It has been confirmed that similar to other viruses, once a person is infected, it takes up to two weeks to develop symptoms; if that is the case, then a person can develop a mild flu-like illness, which according to the first Chinese analysis, this proportion was estimated to be up to $81 \%$ (Novel Coronavirus Epidemiology Response, 2020). However, those entering severe and critical states might be hospitalised and it takes several days until a fatality occurs. In view of that, obtaining the CFR by using the proportion of current deaths to current cases is a misleading indicator because the actual deaths from current cases will be reported later (Battegay et al., 2020).

Following the recommendation by Battegay et al. (2020), the third problem has been addressed by estimating the CFR as follows:

$\operatorname{CFR}_{i}=\frac{\text { Total deaths }}{i t}$

This measure is larger than a current indicator, yet it might be more accurate. Figure 2 shows the CFR for three countries. It is clear that the larger the lag in the total cases the larger the CFR will become. However, it is noticeable that they tend towards convergence. 
FIGURE 2

\section{CFR FOR THE WORLD}

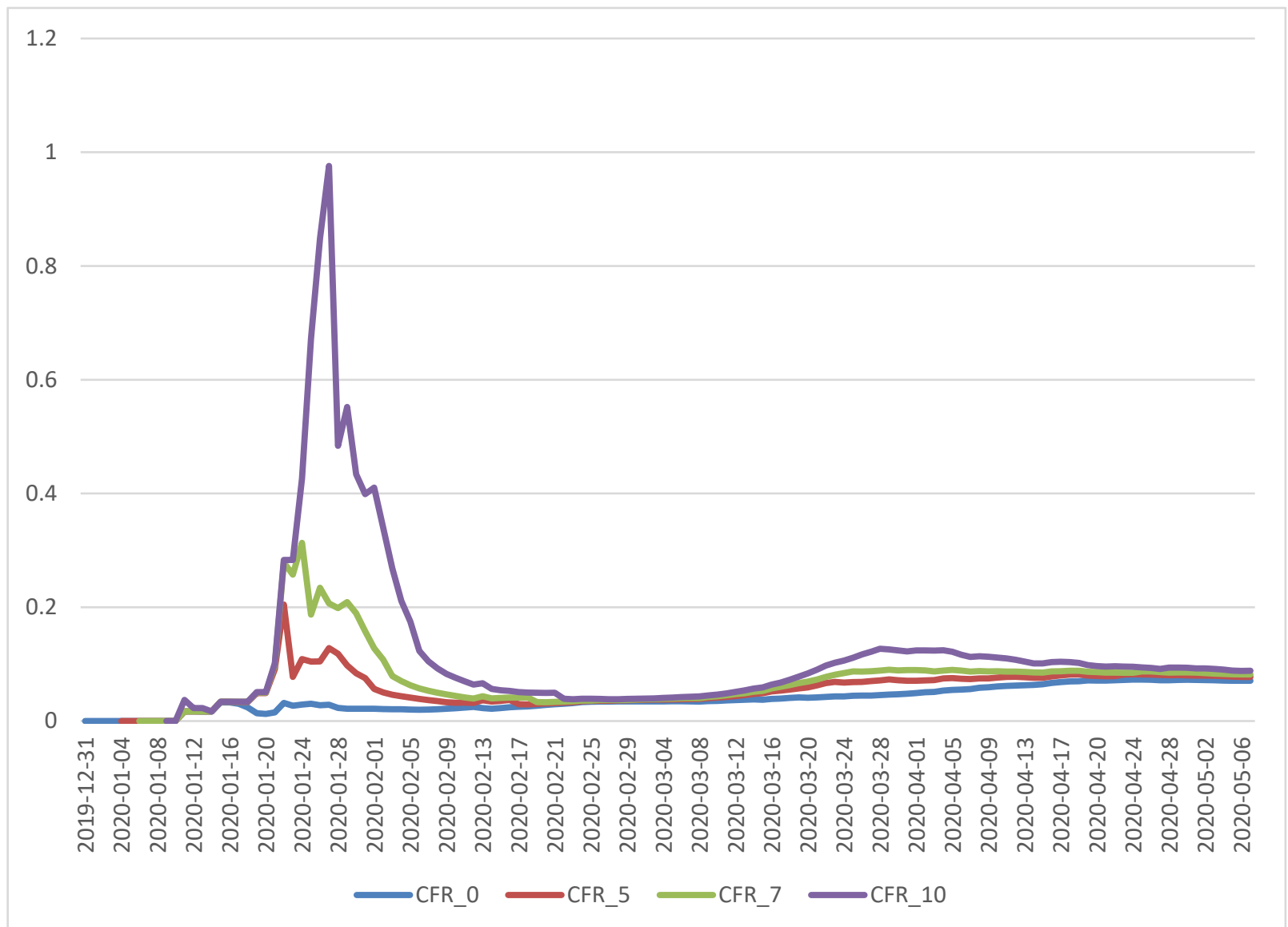

Source: own elaboration.

In Table 1, the values at the beginning and end of the period are shown. For the three indicators, the CFR is higher at the end of the period and the differences among them diminished.

TABLE 1

CFR FOR THE WORLD

\begin{tabular}{|l|l|l|l|l|}
\hline Date & CFR_0 & \multicolumn{1}{l}{ CFR_5 } & CFR_7 & CFR_10 \\
\hline $2020-01-11$ & $1.7 \%$ & $1.7 \%$ & $1.7 \%$ & $3.7 \%$ \\
\hline $2020-05-07$ & $7.1 \%$ & $7.8 \%$ & $8.2 \%$ & $8.8 \%$ \\
\hline
\end{tabular}

Source: Own estimation with data from Ourworldindata.org

It is also important to mention that the first reported death came on the $12^{\text {th }}$ day after the first case was registered. Therefore, it is important to use a lagged number of cases for a better estimate.

The model used is as follows:

CFR $R_{i}=\beta_{i} X_{i}+\delta_{0}$ Testsmillion $+\varepsilon_{i}$

where $C F R_{i}$ is the the Case Fatality Rate ranking for country $i$; for the full CFR per country, see is a vector of variables corresponding to health indicators, both on infrastructure and on population health, which 
could help explain the difference in CFR across countries, such as obesity, diabetes, presence of elderly people and other factors. It is important to mention that not all the variables are included at the same time in the models to prevent biases, especially by correlation among health expenditure, infrastructure and population health indicators; the variables are not included in the model at the same time.

The number of tests per million inhabitants is also included as it has been claimed that the only way to decrease the CFR in the long-term is to massify the applied tests (OECD, 2020). Finally, considering that quarantine measures have been considered a determinant factor for fatality rate, the Stringency index by Thomas et al. (2020) is also added as an explanatory variable. This index is a wide indicator of all the different social measures taken by governments to reduce the speed of spread, such as schools closing, cancelation of public events, closing borders, etc. It is available daily for several countries. It gives a weight to each measure taken with the highest level for any given country being 100 .

\section{Cross-Section Model Specification}

These models are estimated by ordinary least squares (OLS) in Stata. The first model uses as a dependent variable the total cases per million inhabitants and the second model uses the total of deaths per million inhabitants. The aim of this model is to show a robust statistical correlation between cases, death and the explanatory variables that were statistically significant in the first model. The models are specified as follows:

Total cases per million m $=\beta_{0}+\beta_{i} X_{i}+\varepsilon_{i}$

Total deaths per million ${ }_{i}=\beta_{0}+\beta_{i} X_{i}+\varepsilon_{i}$

\section{Panel Fixed Effects Models}

Finally, a group of panel data estimations have been made for evaluating greater robustness for the models specified above. Panel data models can potentially include a larger number of data by combining cross-section and time-series analysis. The cross-section models were used to be able to link the dependent variables, varying daily to annual variables by using one static picture at the data. Instead, for the panel analysis, only data varying daily are used, including cases, tests, deaths and the Stringency index. Given the type of data, these models allow the use of dynamic variables. Thus, first differences of the dependent variables are employed. Natural logarithms are used to find elasticities.

The models are specified as follows:

$n\left(\right.$ CFR $_{i t}-$ CFR $\left._{i t-1}\right)=\alpha_{i}+\beta_{0}+\beta_{1}$ lnNewtestsmillion $_{i t-7}+$

$\beta_{2}$ lnStringencyIndex ${ }_{i t}^{2}+\delta_{0}$ Time $_{t}+\varepsilon_{i t}$

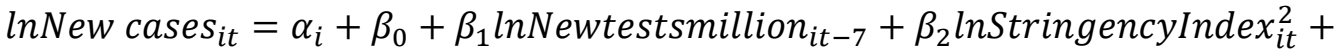

$\delta_{0}$ Time $_{t}+\varepsilon_{i t}$

lnNew deaths $_{i t}=\alpha_{i}+\beta_{1}$ lnNewtestsmillion $_{i t-7}+\beta_{2}$ lnStringencyIndex $_{i t}^{2}+$ $\delta_{0}$ Time $_{t}+\varepsilon_{i t}$

For all the models, there are two explanatory variables: the 7th lag of new tests per million inhabitants and the square of the Stringency index. The seventh lag of new tests per million is used given the claims that early testing reduces the chances of increased infections (OECD, 2020). At the same time, similar to CFR, it is considered the time for the virus to develop; for instance, a person who is asymptomatic today might develop symptoms within a week. Mizumoto et al. (2020) estimate a range of 5.5-9.5 days for incubation, yet this is still uncertain. There are cases in which people might show symptoms and die within a few days ${ }^{8}$. 
Given the difficulties determining the best lag to consider, two choices are shown: the 7th and the 15th. Regarding quarantine measures, many countries converge to similar levels in the index at the end of the period, yet squaring the variable allows us to model the fact that the index has a maximum and its marginal effect is smaller in the time.

Additionally, countries taking early measures should be able to contain the spread to a larger extent; thus, this is modelled through the initial larger marginal effect on the dependent variables of a squared variable.

In Equation (5), the model has as a dependent variable the natural logarithm of the first difference in CFR. In Equation (6), the dependent variable is the natural logarithm of new COVID-19 cases per million (first difference of total COVID-19 cases per million) and, in a similar fashion, the natural logarithm of new deaths per million (first difference of total

TABLE 2 SUMMARY STATISTICS

\begin{tabular}{|c|c|c|c|c|}
\hline & Mean & Maximum & Minimum & Standard Deviation \\
\hline & \multicolumn{4}{|c|}{ Panel Data } \\
\hline CFR & 0.0683694 & 9.5 & \begin{tabular}{r|}
0 \\
\end{tabular} & 0.1837786 \\
\hline New cases per million & 12.49621 & 4944.376 & -139.488 & 66.70643 \\
\hline New deaths per million & 0.5867564 & 200.04 & 0 & 3.860438 \\
\hline New tests per million & 325.8418 & 7285 & 0 & 566.0734 \\
\hline \multirow{2}{*}{ Stringency index } & 32.84637 & 100 & 0 & 37.00693 \\
\hline & \multicolumn{4}{|c|}{ Cross-section } \\
\hline CFR & 0.0633442 & 0.2009389 & 0.0084971 & 0.0438073 \\
\hline Total tests per million & 14153.18 & 80726.73 & 0 & 16803.75 \\
\hline $\begin{array}{l}\text { Health expenditure as GDP } \\
\text { percentage }(\%)\end{array}$ & 6.869014 & 17.1 & 2.3 & 3.380769 \\
\hline Stringency index & 79.54732 & 97.14 & 0 & 20.52645 \\
\hline Total deaths per million & 85.62903 & 719.523 & 0.788 & 155.176 \\
\hline Total cases per million & 1274.181 & 9719.796 & 34.875 & 1664.223 \\
\hline
\end{tabular}

Source: Own elaboration

As seen in Table 2, the mean CFR is similar for both datasets (0.0683694 and 0.0633442), which implies that the CFR keeps its trend in the time period analysed. However, this is not the case for the coefficient of variation ${ }^{9}$, which is greater for the panel data (268.80) than for the cross-section (69.15) and explained by the different results in the period for the different countries.

It is also worth noting that the maximum CFR in the panel data can be higher than 1 . The reason is that in countries with very explosive growth, the total cases confirmed one week is less than the total deaths occurring the following week, by which time the confirmed cases grew exponentially.

\section{RESULTS}

In Table 3, the results for the ordinal probit model are presented. The infrastructure variables and the population's health indicators were not statistically significant; instead, an indicator for health expenditure was used. B e caus e health expenditure is related to infrastructure endowments and some population health indicators are related to expenditure, the variables on infrastructure/population health and expenditure are alternatively used. Full tables with all the considered variables are shown in the Additional files 2 and 3. 
TABLE 3

ESTIMATION RESULTS FROM THE ORDINAL PROBIT MODEL

\begin{tabular}{|c|c|c|c|c|}
\hline & (1) & (2) & (3) & (4) \\
\hline $\begin{array}{l}\text { Dependent Variable: CFR } \\
\text { Ranking }\end{array}$ & Base line_71 & $\begin{array}{l}\text { Base } \\
\text { line_OECD }\end{array}$ & Stringency_71 & $\begin{array}{l}\text { Stringency } \\
\text { OECD }\end{array}$ \\
\hline \multirow[t]{2}{*}{ Total tests per million } & $-0.00002 * *$ & $-0.00002 *$ & $-0.00002 * *$ & -0.00002 \\
\hline & $(0.00001)$ & $(0.00001)$ & $(0.00001)$ & $(0.00001)$ \\
\hline \multirow{2}{*}{$\begin{array}{l}\text { Health expenditure as GDP } \\
\text { percentage }\end{array}$} & $0.1011467 * * *$ & 0.08313 & $0.09931 * * *$ & 0.08679 \\
\hline & $(0.03891)$ & $(0.06384)$ & $(0.03801)$ & $(0.06405)$ \\
\hline \multirow[t]{2}{*}{ Stringency index } & & & 0.00404 & 0.00947 \\
\hline & & & $(0.00600)$ & $(0.01095)$ \\
\hline$N$ & 71 & 31 & 71 & 31 \\
\hline
\end{tabular}

Source: Own elaboration

Columns 1 and 3 present the results for the sample with 70 countries while columns 2 and 4 present those for the OECD members. A negative sign is shown between CFR ranking and the total test per million; therefore, countries running more tests observed a larger probability of having a lower CFR. In contrast, countries with larger expenditures on health observed a larger probability of having a higher CFR. For the OECD subsample, only the first variable was statistically significant. Finally, the Stringency index is not statistically significant in any case.

Table 4 displays the results from the cross-section model. In this model, only the explanatory variables that were statistically significant in the previous model were used. Columns 4 and 5 show that there is a positive correlation between the number of tests and the total cases, which only confirms that the countries running more tests are identifying more cases; however, this is not directly related to the number of deaths. In other words, the total tests per million did not show a significant correlation with the number of fatalities.

Health expenditure is statistically significant for all the models. This is definitively related to a problem of COVID-19 cases and deaths identification and records rather than to causation. In other words, higher health expenditure as a proportion of GDP cannot be a causal factor for larger contagions and deaths related to COVID-19, but the positive correlation confirms that countries spending more on health are identifying more cases and deaths. For instance, this variable has a larger coefficient for OECD members, from which the majority comprise developed countries and spends more on health as a GDP proportion. Namely, for OECD countries, the average was $8.8 \%$ while for non-OECD countries it was 5.32 although the difference in purchasing power parity dollars is wider; on average, OECD countries spent $\$ 2547$ USD vs $\$ 1088$ USD in non-OECD countries. 
TABLE 4

ESTIMATION RESULTS FOR CROSS-SECTIONAL MODELS

\begin{tabular}{|c|c|c|c|c|}
\hline \multirow[t]{2}{*}{ Dependent Variable: } & \multicolumn{2}{|c|}{$\begin{array}{l}\text { Total Cases per Million } \\
\text { Inhabitants }\end{array}$} & \multicolumn{2}{|c|}{$\begin{array}{l}\text { Total Death per Million } \\
\text { Inhabitants }\end{array}$} \\
\hline & (5) & (6) & (7) & (8) \\
\hline & 71 & OECD & 71 & OECD \\
\hline \multirow[t]{2}{*}{ Total tests per million } & $0.03913 * * *$ & $0.05536 * * *$ & 0.00160 & 0.00162 \\
\hline & $(0.01074)$ & $(0.01237)$ & $(0.00100)$ & $(0.00181)$ \\
\hline \multirow[t]{2}{*}{ Health expenditure as GDP } & $105.66169 * *$ & $171.89538 * *$ & $15.23655 * * *$ & $20.86109^{*}$ \\
\hline & $(52.48922)$ & $(71.77250)$ & $(4.89474)$ & $(10.51117)$ \\
\hline \multirow[t]{2}{*}{ Stringency index } & 2.04969 & $25.49470 * *$ & 0.36923 & 2.27619 \\
\hline & $(8.47057)$ & $(12.33977)$ & $(0.78990)$ & $(1.80717)$ \\
\hline \multirow[t]{2}{*}{ Constant } & -234.87260 & $-.0176 \mathrm{e}+03 * *$ & -78.83186 & -264.24963 \\
\hline & $(776.83271)$ & $(1284.56380)$ & $(72.44148)$ & $(188.12600)$ \\
\hline$N$ & 71 & 31 & 71 & 31 \\
\hline$R^{2}$ & 0.259 & 0.482 & 0.197 & 0.171 \\
\hline
\end{tabular}

Source: own elaboration

Finally, the results from the panel data analysis are shown in Table 5. Fixed effects were chosen over random effects using the Hausman test as the criterion. In column 9, new tests per thousand inhabitants show a negative correlation with first difference of CFR, which means that countries applying more tests per capita showed smaller differences on CFR across the period; that is, CFR observed a trend of reduction. Consequently, this supports that the widespread application of tests to reduce the fatality rate has been effective. In addition, it is also expected that CFR from countries identifying more positive cases converge to the real CFR, given that massive testing will give the true proportion between contagions and deaths. In the same model, the Stringency index coefficient is not statistically significant and the trend is negative, as expected, because it should be smaller over time. It is important to note that the panel data are unbalanced and all countries with available data are included, which are mostly from Europe, Asia, North America and South America.

In columns 10 and 11, the dependent variables showed a high positive correlation with new tests, similar to the previous models. This means that the correlation between testing the new deaths and new cases is sustained over time. Meanwhile, the Stringency index showed a negative coefficient; nonetheless, it is only statistically significant in column 11, with new deaths as the dependent variable. Therefore, it is confirmed that stringency measures have helped reduce the number of COVID-19 deaths, but there is no statistical evidence of being effective in reducing the number of new cases. The trend means that new deaths have a significantly positive trend, i.e. they are still growing. 
TABLE 5

PANEL DATA ESTIMATION RESULTS

\begin{tabular}{|c|c|c|c|c|c|c|}
\hline & (9) & (10) & (11) & (12) & (13) & (14) \\
\hline $\begin{array}{l}\text { Dependent } \\
\text { variable }\end{array}$ & $\begin{array}{l}\text { Ln CFR0- } \\
\text { CFR-1 }\end{array}$ & $\begin{array}{l}\text { Ln New } \\
\text { cases per } \\
\text { million }\end{array}$ & $\begin{array}{l}\text { Ln New } \\
\text { deaths per } \\
\text { million }\end{array}$ & $\begin{array}{l}\text { Ln CFR0- } \\
\text { CFR-1 }\end{array}$ & $\begin{array}{l}\text { Ln New } \\
\text { cases per } \\
\text { million }\end{array}$ & $\begin{array}{l}\text { Ln New } \\
\text { deaths per } \\
\text { million }\end{array}$ \\
\hline \multirow{2}{*}{$\begin{array}{l}\text { Ln Stringency } \\
\text { index } 2\end{array}$} & 0.0623 & -0.0287 & $-0.0671 * *$ & 0.0502 & -0.0240 & $-0.0643 * *$ \\
\hline & $(0.0590)$ & $(0.0274)$ & $(0.0266)$ & $(0.0653)$ & $(0.0287)$ & $(0.0251)$ \\
\hline \multirow[t]{2}{*}{ Time } & $-0.0571 * * *$ & $-0.0171 * *$ & $0.0270 * * *$ & $-0.0585 * * *$ & $-0.0209 * *$ & $0.0149 *$ \\
\hline & $(0.0131)$ & $(0.0070)$ & $(0.0074)$ & $(0.0168)$ & $(0.0092)$ & $(0.0081)$ \\
\hline \multirow{2}{*}{$\begin{array}{l}\text { Ln new tests } \\
\text { per million } \\
\text { inhabitantst-7 }\end{array}$} & $-0.8063 * * *$ & $0.6508 * * *$ & $0.4765 * * *$ & & & \\
\hline & $(0.1827)$ & $(0.0746)$ & $(0.0907)$ & & & \\
\hline \multirow{3}{*}{$\begin{array}{l}\text { Ln new tests } \\
\text { per million } \\
\text { inhabitantst-15 }\end{array}$} & & & & $-0.6123 * * *$ & $0.3515 * * *$ & $0.3644 * * *$ \\
\hline & & & & & & \\
\hline & & & & $(0.1919)$ & $(0.0836)$ & $(0.0906)$ \\
\hline \multirow[t]{2}{*}{ Constant } & $1253.6235^{* * *}$ & $376.2262 * *$ & $-597.7731 * * *$ & $1282.9684 * * *$ & $459.9860 * *$ & $-329.5989 *$ \\
\hline & -287.5767 & -153.4644 & -162.1304 & $(368.6225)$ & $(202.0653)$ & $(179.0541)$ \\
\hline Observations & 109 & 316 & 190 & 92 & 243 & 160 \\
\hline$N$ & 48 & 64 & 53 & 42 & 59 & 49 \\
\hline$R^{2}$ & 0.689 & 0.381 & 0.541 & 0.641 & 0.124 & 0.392 \\
\hline
\end{tabular}

Source: Own estimation

As a robustness check, a longer lag has been included - the 15th lag of new tests per million - to control if there is any change over time. The results are very consistent: the variables kept the same sign and they remained statistically significant. The value of $\mathrm{R}^{2}$ diminished for the three models, which can be affected by the smaller number of observations and countries included.

\section{DISCUSSION}

Our results support the WHO recommendations to increase testing and tracking of COVID-19 cases in all countries, given its definitive impact on reducing the CFR. In line with Stojkoski et al. (2020), we found that the countries' expenditure on health as well as their development level is positively related to CFR, cases and deaths, which cannot be interpreted as causation, but indicates that developing countries do not track enough cases yet. Consequently, we claimed that there is an under-identification of data given the positive correlation between cases and deaths and testing, meaning that testing is still reactive and with little identification of asymptomatic cases, which is also highlighted by the OECD (2020) and the WHO (2020). Furthermore, given the under identification of cases, it is still very difficult to identify the country-specific drivers for contagions and CFR.

Lockdown measures, according to the Stringency index, were shown to be effective at reducing the number of new deaths but not for new cases and deaths. Therefore, the results support the proposition 
to stop severe lockdown measures given the heavy economic losses and burdens for governments, which in turn will not significantly reduce the number of cases and CFR.

One significant limitation of this study is the usage of aggregated national data, rather than regional data, which could have helped identify regional socioeconomic drivers for the COVID-19 spread and CFR given that in some countries the cases seemed to be very concentrated within a few cities or regions.

\section{CONCLUSIONS}

Testing proved to be a significant factor in decreasing CFR; thus, it should be supported as the main strategy to follow for pandemic control in the medium- and long-term. The findings suggest that there is a large under-identification of COVID-19 cases, especially for developing countries, which compromises the long-term control of the pandemic. Thus, it is essential to make agreements with all nations to keep increasing the testing for further knowledge of COVID-19 and its spreading drivers at the national level, allowing tailored responses.

The data show a particular performance for the cross-section in which the coefficient of variation is very low, but this trend changes when using panel data in which the coefficient of variation shows a significant change. In this case, the panel data regression analysis captures the idiosyncratic errors in this time period, with a more precise estimation of the effects of the test per million habitants.

Using the Stringency index, it was found that lockdown measures have been effective in reducing the number of new deaths although they showed no impact on new cases and CFR reduction. This has public policy implications as lockdown measures generate great economic losses and are already inducing economic crises all over the world, with greater affectations for developing and less developed countries (Loayza, 2020).

Another general conclusion is that the availability of data for all countries is still very limited, which hinders further analysis of COVID-19 spread and CFR drivers at the national level. The question remains unanswered as to whether countries with larger proportions of the population aged over 65 or over 80 , such as Japan or Italy, are more susceptible to a higher CFR. Additionally, at the aggregate level, it was not possible to link variables such as obesity and diabetes with a higher CFR or number of deaths. Likewise, there is a significant difference in infrastructure endowments across the sample used; nevertheless, the CFR or the number of deaths appeared to be statistically explained by these factors.

The pandemic is still developing and there are countries in which the highest peak of contagions has not yet been reached; thus, further analysis for narrowed public policies will be needed. The current recommendation from the WHO, OECD and other medical bodies to increase testing proved to be the wiser path to follow at the moment.

\section{ENDNOTES}

1. Accessed 17th May:

https://www.forbes.com/sites/joshuacohen/2020/05/13/as-a-tiny-nation-tests-all-inhabitants-forcoronavirus-the-world-awaits-the-results/?fbclid=IwAR3CnpQxnW9sG-_o0gYUyC-

AqZw_3EglvZ4LafmSYtlb7mFz3YdRyg- AFRM\#7068808a2378

2. Accessed 13th May 2020 at:

https://blogs.worldbank.org/voices/scaling-covid-19-crisis-response-now-will-avoid-higher-costs-later

3. Accessed 13th May 2020:

https://www.ilo.org/global/about-the-ilo/newsroom/news/WCMS_627189/lang--en/index.htm

majority of cases are concentrated in developed countries while developing economies only account for approximately $20 \%$ of the cases. Africa registered only $1 \%$ of worldwide cases.

4. https://github.com/owid/covid-19-data/find/master

5. https://www.oecd.org/els/health-systems/health-data.htm

6. https://www.who.int/healthinfo/en/

7. https://analysis.covid19healthsystem.org/index.php/2020/06/04/how-comparable-is-covid-19-mortality- 
across-countries/

8. Belgian girl becomes Europe's youngest coronavirus victim: media. Available at: https://www.reuters.com/article/us-health-coronavirus-belgium-death/belgian-girl-becomes-europes-young est-coronavirus-victim-media-idUSKBN21I1W8

COVID-19 deaths per million). By using weighted variables per million inhabitants, the population size differences across countries are addressed.

All the variables and their summary statistics are shown in Table 2.

9. (Standard Deviation / Mean)*100

\section{REFERENCES}

Battegay, M., Kuehl, R., Tschudin-Sutter, S., Hirsch, H.H., Widmer, A.F., \& Neher, R.A. (2020). 2019Novel Coronavirus (2019-nCoV): Estimating the case fatality rate - a word of caution. Swiss Med Wkly. DOI: https://doi.org/10.4414/smw.2020.20203

CDC (Center for Disease Control and Prevention). (2020). Serology testing for COVID-19. Retrieved May 15, 2020, from https://www.cdc.gov/coronavirus/2019-ncov/lab/serology-testing.html

Heneghan, C., Brassey, J., \& Jefferson, T. (2020). COVID-19: What proportion are asymptomatic? Retrieved from https://www.who.int/healthinfo/en/

Loayza, N. (2020). Smart containment and mitigation measures to confront the COVID-19 pandemic: Tailoring the pandemic response to the realities of developing countries. World Bank blogs. Retrieved May 15, 2020, from https://blogs.worldbank.org/developmenttalk/smart-containmentand-mitigation-measures-confront-covid-19-pandemic-tailoring

Mizumoto, K., Kagaya, K., Zarebski, A., \& Chowell, G. (2020). Estimating the asymptomatic proportion of coronavirus disease 2019 (COVID-19) cases on board the Diamond Princess cruise ship, Yokohama, Japan. Euro Surveill, 25(10). https://doi.org/10.2807/15607917.ES.2020.25.10.2000180

Owid/Covid-19. (n.d.). Retrieved May 19, 2020, from https://github.com/owid/covid-19-data/find/master Sánchez, E. (2020). COVID-19 science: Why testing is so important. American Heart Association. Retrieved May 15, 2020, https://www.heart.org/en/news/2020/04/02/covid-19-science-whytesting-is-so-important

Stojkoski, V., Utkovski, Z., Jolakoski, P., Tevdovski, O., \& Kocarev, L. (2020). The socio-economic determinants of the coronavirus disease (COVID-19) pandemic. medRxiv preprint. doi: https://doi.org/10.1101/2020.04.15.20066068

The Novel Coronavirus Pneumonia Emergency Response Epidemiology Team. (2020). Vital Surveillances: The Epidemiological Characteristics of an Outbreak of 2019 Novel Coronavirus Diseases (COVID-19) — China.

Thomas, H., Angrist, N., Kira, B., Petherick, A., Phillips, T., \& Webster, S. (2020, April 29). Variation in Government Responses to COVID-19. Version 5.0. Blavatnik School of Government Working Paper. Retrieved from www.bsg.ox.ac.uk/covidtracker

World Health Organisation. (2020, April 16). Considerations in adjusting public health and social measures in the context of COVID-19. Retrieved fromhttps:/www.who.int/publications-detail/considerations-inadjusting-public-health-and-social-measures-in-the-context-of-covid-19-interim-guidance

\section{APPENDIX: LIST OF ABBREVIATIONS}

CFR - Case Fatality Rate

OECD - Organisation for Economic Cooperation and Development WHO - World Health Organisation

ILO - International Labour Organization 